\title{
HOW EFFECTIVE CORPORATE GOVERNANCE COULD PREVENT CRISES
}

\author{
Nina BRATFALEAN ${ }^{a *}$, Alecxandrina DEACONU ${ }^{b}$ \\ ${ }^{a}{ }^{b}$ Bucharest University of Economic Studies, Romania
}

DOI: $10.24818 / \mathrm{IMC} / 2020 / 04.11$

\begin{abstract}
The study has been prepared as a potential crisis-response program, or guidelines aimed at reducing the probability of crises, that the boards normally use, or could use.

The contents are based on empirical academic research and on the practical experience of authors. Additionally, the information about emerging market companies' actual crisis management practices was drawn from trainings and workshops during the past 12 years within BMW Group in more than 10 Central South-Eastern European countries, as well as Middle East and North Africa, together with the rigorous study of the materials in the bibliography.

Conceptually, we use a contingency approach looking at various specific situations and the factors that influence them. From here arise many practical ideas and potential solutions for crisis management and involvement of the board.

The conclusion runs towards the fact that careful screening of external, as well as internal factors the latter could sometimes be of more danger - of a company by the board could prevent the passing through a crisis of that respective company.

Both in mature companies, global corporations and in start-ups, well-established corporate governance is a key factor in preventing crises or in preparing the company for entering and exiting the crises with minimum losses possible.
\end{abstract}

KEYWORDS: board of directors, corporate governance, emerging economies, involvement of the board, prevention of crisis.

\section{INTRODUCTION}

Experience and business life prove that some corporations simply face better certain difficulties arising in business cycles and in various industries. It is never possible to be in the right spot at the right time with the right strategy and people. Thus, a crisis is about to happen sooner than later this is almost a fact. Key point is how the management will deal with it.

A crisis is a rough test for the corporate governance structure of any company, regardless of the legal framework, ownership structure or industry it acts in. In a crisis period all weak points are vividly exposed and whatever procedure, policy or department has frictions or does not function well is immediately punished.

Not even in times of wealth, yet even less in crisis or tensioned times, a company will perform properly if its board is malfunctioning.

Proper corporate governance is key to any company, regardless of country, industry, size or type of ownership. In emerging economies many board practices cannot reach the full potential of the benefits that they could come with. It is well known that there is no universal corporate governance model and that corporate governance must be adapted and practiced in specific, customized ways for every company.

\footnotetext{
* Corresponding author. E-mail address: nina@macsys.eu
} 
The corporate governance principles of transparency, accountability and independent supervision of management performance should be tailored to specific companies' needs, depending on the structure of the ownership, on the key business model and on the strategy; also, to significantly consider are the requirements of capital markets, lenders and regulators; last but not least, cultural influences are also not to be neglected (Klemash et al., 2018)

Corporate governance is an ample concept, encompassing many possible definitions.

One useful definition is that corporate governance establishes the structures of accountability, responsibility and transparency at the helm of the company and defines the role of boards as well as management (International Finance Corporation, n.d.)

Translated to real life, we could affirm that with good corporate governance the best-fit procedures and alignment systems are implemented and respected between management and owners, as well as and other stakeholders and employees. Moreover, proper governance means that information flows smoothly and transparently and that accountability has been built between the different layers of the organization.

Also, with proper governance internal controls and risk-management practices are set up.

When we ponder over the crisis management, good corporate governance permits the senior management and the members of the board to detect potential arising problems and to prevent them from transforming into a huge crisis or into a disaster for the company (Westlake, 2017)

When a problem arises and good corporate governance system is in place (e.g. Covid19), then the responsibilities, the accountability degree, the roles and the immediate action plan of each decisionmakers are clear; every involved party knows what to do, all contingencies are discussed openly, and thus fast and efficient solutions can be decided upon.

To evaluate if such systems and good corporate governance exist in companies, we could analyze four factors that shape corporate governance systems all over the world (Steger \& Nedopil, 2010):

- Personalities, experiences, values, style of leadership of the company founder or of the CEO.

- Type of company ownership: there are crucial differences between the way corporate governance works within the family business or within shareholding structures that are fragmented.

- The key business model and the competitive focus, as well as the company's lifetime and potential (or existing) global exposure.

- The entire set of cultural and legal framework.

In this article we consider as being relevant the difference between executives and non-executives on the board and between insiders and outsiders of the company.

Insiders are the board members who have a connection to the company, being either substantial investors or having a previous management role within the company.

Outsiders are the board members who have no direct link to the company and simply carry and perform their board role.

The difference between non-executive and executive directors is quite obvious, in that the executive directors hold a management position in the same company, while the non-executive do not.

The independent director - based on my experience and understanding - is a non-executive director, mostly an outsider, whose main function - and strength - is his / her ability to make neutral decisions and bring a non-biased input in the sole benefit of the company.

The relevance of these distinctions lays in the potential divergence of interests, which often result in lack of transparency, in difficulties in communication and in web-politicking (Steger \& Nedopil, 2015). 


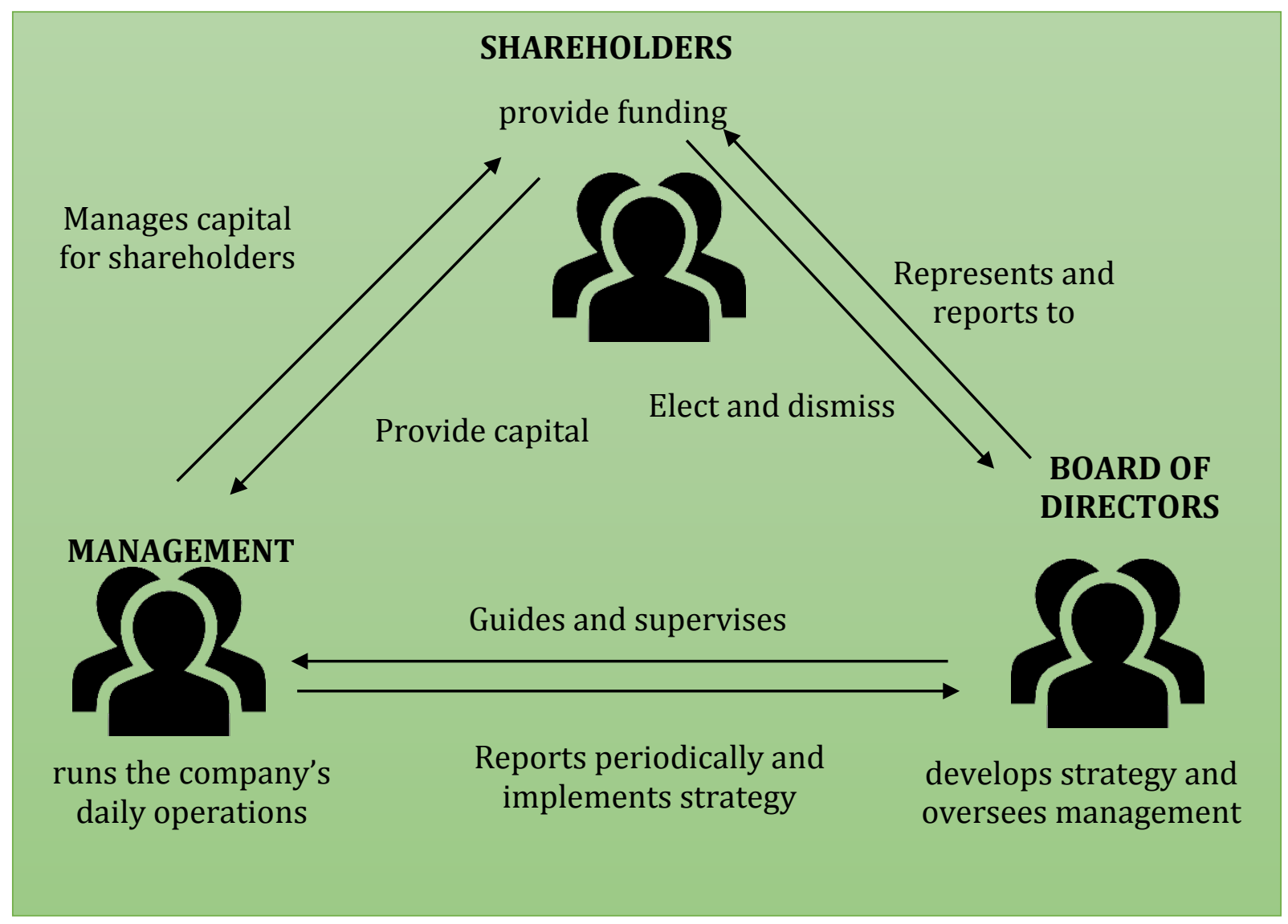

Figure 1. Corporate Governance Structure and Its Rapport with Key Stakeholders Source: Adapted after "The Incredible Adventures of Carla'

Often, in moments of crisis, the sides start forming and often corporate governance cannot work if a party of insiders and executives control the board; this might be the case when the group of insiders have an obvious vested interest in a system that functions towards the smooth approval of their own decisions and views of how the company should evolve.

More than in normal times, the balance and cooperation between board members and the management should happen in crisis situations. This is one of the topics that we plan to approach later in this paper, analyzing what a well-balanced board means.

For a stronger foundations-laying of our paper, here is an example of a structure of a corporate governance composition and its rapport with the rest of the key stakeholders: shareholders, board of directors, management.

The obvious question converges around the value that the corporate governance system can add to the organization.

We believe that this question can only be answered on a case-by-case basis, namely by analyzing the following factors (Sustainalytics, n.d.)

a) Do the board members add distinctive input to the strategy and do they contribute with new vision or information ref. market trends?

b) Does each of the board members offer a broad information base through their diverse experience levels and professional backgrounds?

c) Does the board facilitate early detection of potential negative developments and are they ready to act fast for the correction of mistakes? This requires effective supervision.

Last but not least, 
d) Is the board focused on a good selection process of the C-level team and, once they are functional and onboarded, does the board provide coaching and support so that a highperforming top management team is established?

Bottomline, although there is not a single best corporate governance system, in general transparency, accountability, and cooperation at the top of the organization add value (White, 2019)

And to all these a crisis is the ultimate test: can the company survive? can the company adapt faster or make better decisions than the rest of the market, given the challenging conditions?

It is the main responsibility of board members to ensure that the corporate governance system works properly and for them to be aware that during a crisis it will be stretched severely.

As we have made a slight distinction between the corporate governance roles in emerging markets as compared to the developed markets, for a proper distinction, here is a parallel analysis between the two, that shades light on why such differentiation is needed (table presented recently during an executive talk of Virtual i Technologies).

Table 1. Developed and Emerging Markets from the Point of View of the Appetite for Corporate Governance

\begin{tabular}{|l|l|}
\hline \multicolumn{1}{|c|}{ DEVELOPED MARKETS } & \multicolumn{1}{c|}{ EMERGING MARKETS } \\
\hline Executive compensation & Regulation of related-party transactions \\
\hline Board compensation & Competence of directors \\
\hline Market-driven incentives & Non-market mechanisms \\
\hline Fiduciary duty to shareholders & Subpar disclosure and internal controls \\
\hline Table 1: Analysis & Independence from controlling shareholders \\
\hline Board-management relations & Capacity gaps for rigorous enforcement \\
\hline Regulating increasingly sophisticated issues & State activism \\
\hline Investor activism & Family - or state-controlled companies \\
\hline Multinationals and listed companies & Nepotism, self-dealing, market abuse \\
\hline Cycles of scandals, corruption, and collapse & Crisis management/reactive management \\
\hline Preventive risk management & \multicolumn{2}{l}{} \\
\hline
\end{tabular}

In conclusion, while companies in developed markets pass inevitably through crises such as cycles of scandals, corruption and collapse, companies in emerging markets are confronted with crises such as nepotism, market abuse, self-dealing.

None of them is 'easier' than the other when it comes to finding back a saner way of functioning, post-crisis.

With the above information background and following this article's declared purpose, we have structured the article in two parts: a first one, corresponding to a brief look at the multiple reasons why a crisis could arise and why a manageable problem transforms into a crisis and analysis; and a second one, corresponding to a brief guideline of how proper corporate governance could prevent crises.

\section{UNDERSTANDING TYPICAL CORPORATE CRISES AND HOW TO (ATTEMPT) TO PREVENT THEM}

Under market conditions companies are inherently exposed to different risks; we define them as 'negative deviations from the plan'. In this respect a crisis is a negative deviation that is so severe and abrupt, that can threaten the very existence of a company (Varfis, 2012)

Crises can show up in many forms and are known to have various causes, from the basic humanrelated ones (e.g. lack of communication, diverging interests, personal egos or revenge, weakness 
and the need to 'save face' etc.) to the more complex one, such as conflicts between board of directors and the management or shareholders.

And the fatal hit is represented by an external-generated crisis, such as Covid19 pandemic and panic.

Typical corporate governance crises have their source in the (lack of) corporate governance of the company.

As most cases in life, crises have one particularly unfortunate feature: they rarely come alone and they 'infect' easily other areas than the starting point, becoming almost impossible to contain in due time. With the unnoticed development of a crisis within the company - unnoticed by neither the board, nor the management - crises can come in mixtures.

For example, an economic crisis makes a client go bankrupt. Or investors withdraw money because sales decline or there is no possibility to keep up production. Or the factory burns down, or a major technical recall of a significant number of vehicles in a car manufacturing facility, or cash becomes scarce, or a supplier does not ship the much-needed inventory, or key payment flows are delayed and there are no more available credit lines from banks, or some raw materials can become scarce because of unexpected natural catastrophe....and more.

A careful and constant board scrutiny of these key factors (alongside the regular duties of the CEO to monitor them) conjunct with global or regional economic and social phenomena and with longterm business experience of the corporate governance members could prevent major falls of the company or have the teams and the resources prepare for rough times.

A possible 'radar' for financial risk should be printed as a big poster in every boardroom (Tenev et al., 2002).

Our own 'red flags' for strategy, extracted from real-life experience and barriers overcoming could be summarized as follows:

1. When change is driven towards Phyrrhic victories and not towards the common-sense approach of the low-hanging fruits (a Phyrrhic victory is a victory with such devastating losses that is tantamount to defeat).

2. When changes in external factors do not lead to changes in strategy proposals by the management.

3. When strategy and internal capacity do not correspond to one another.

4. When functional, business and corporate strategy to not feed into one another.

5. When the ratio cost/ income is very high; that is, high productivity, poor performance.

6. When the board did not check/ look at the strategy during the past half a year.

7. When competitive benchmarks are much ahead the actual results of the company.

The real challenge of the board is to find the very first source of the crisis and to stop its spreading at the macro level as well as at the firm level.

The seven factors listed above are some basic ones which, paradoxically, tend to be overlooked sometimes, as 'internal' and 'power-fights' take place within the company or within the board and they blind temporarily what should be major interests. 


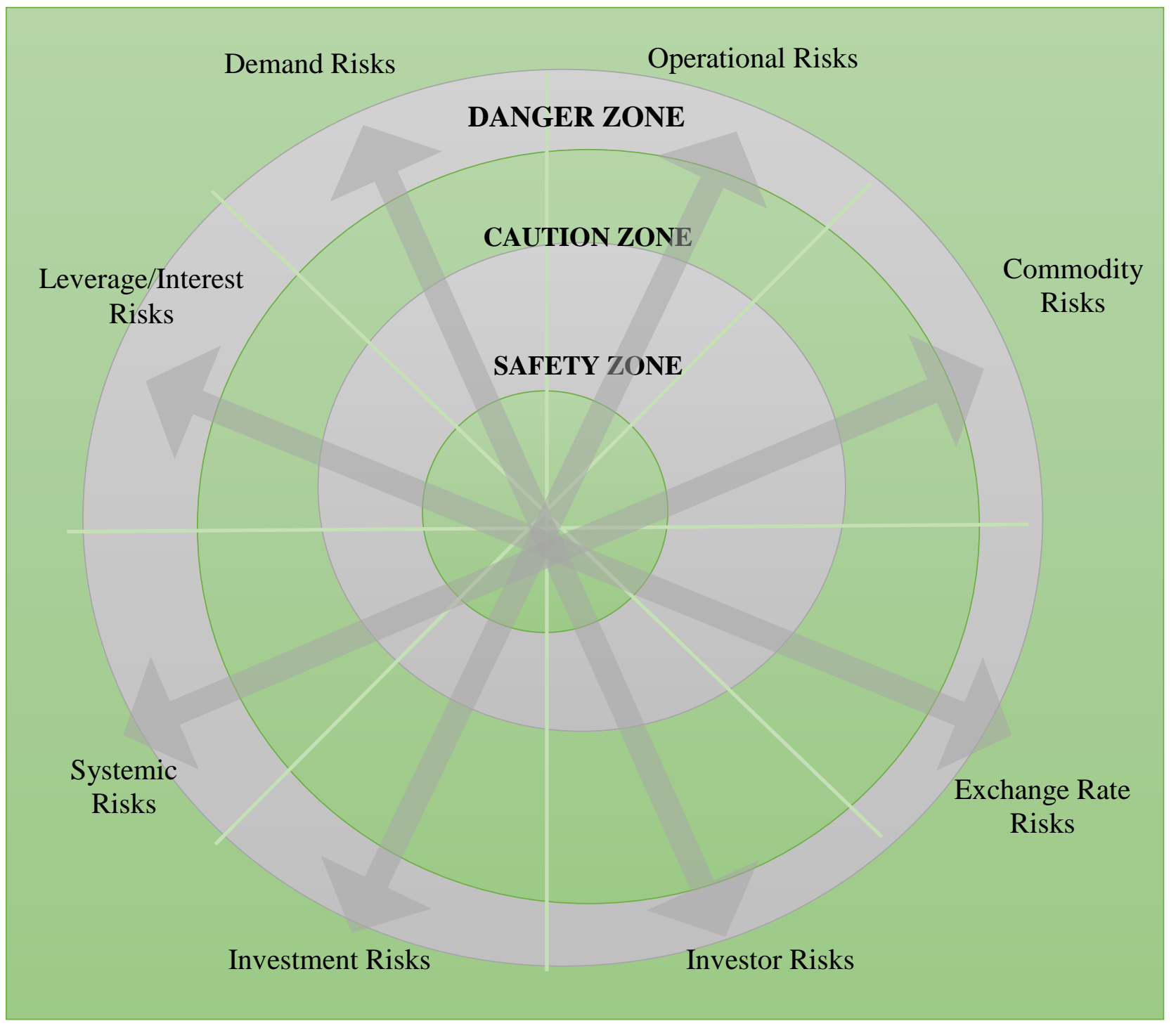

Figure 2. Financial Risk Radar

Source: author's own adaptation from the above-listed source

\section{HOW APARENTLY MANAGEABLE PROBLEMS CAN TURN INTO CRISES}

Surely, most crises do not come 'unprepared'. While there could be several blind spots, a total opaque view cannot exist; or if it does, then it means that neither the company managers, nor the board directors paid real attention to the business environment.

Normally early warning signals, even red flags arise before an initially manageable problem turns into a full-dimension crisis.

We would offer three potential major reasons. Major by their disastrous effect on the company, with high probability of happening when least expected, should the board not monitor vigilantly such factors.

a) A basic - and, somehow, funny reason (because its predictability and ease of 'we should have prevented it' - is the weak communication with the stakeholders, connected with social media presence.

We are also entering into an era of citizen journalism, where anyone with a smartphone can become a publisher (Boytsun, Deloof \& Matthyssens, 2010). 
Audiences expect access to timely and accurate information, especially on 'hot' topics that could impact society or certain groups of people and that are caused by a (visible) company.

If a company does not communicate in time, or react immediately and openly (or strategically) to potential damaging news inflated overnight, the result can be disastrous: stakeholders would get panicked, would ask for information, would add pressure to the CEO and the PR department, would infuriate the board members, would reach the years of the investors and so on and so forth. A winter ball that becomes bigger and bigger, stimulated by the mere non-response of the company.

How could the board prevent this?

By stimulating (or demanding) a proactive communication culture, a mindset of (smart) transparency and by always being informed of the trends and vicious tendencies of the third parties.

b) Corporate-political barriers to recognizing crises early are the most "macro" type of barriers. They include political influences on the corporate decision-making process, which impede rational thinking.

Boards which are not able to detect (or even accept) political interference or strategy submission should expect that manageable problems could turn into deep crises, once the stakeholders - and the general public - finds a thread of the situation.

Also, politically subordinated boards, or boards controlled by politically serving members, are keen to maintain the status quo of the company, thus losing competitive edge and/ or reacting late to the market demands.

How could the board prevent this?

The bad news is that this kind of crises can hardly be prevented by the board members if there is political dominance.

c) Psychological barriers that none seriously thinks about.

The basic truth is that humans don't like discomforting news. There is an innate (?) tendency to listen or hear or read good news or information that confirms one's worldview (e.g., to support decisions already taken - in the buying cycle this is considered to be the 'reinforce purchase' attitude - the confirmation that you have bought the right product with the right price).

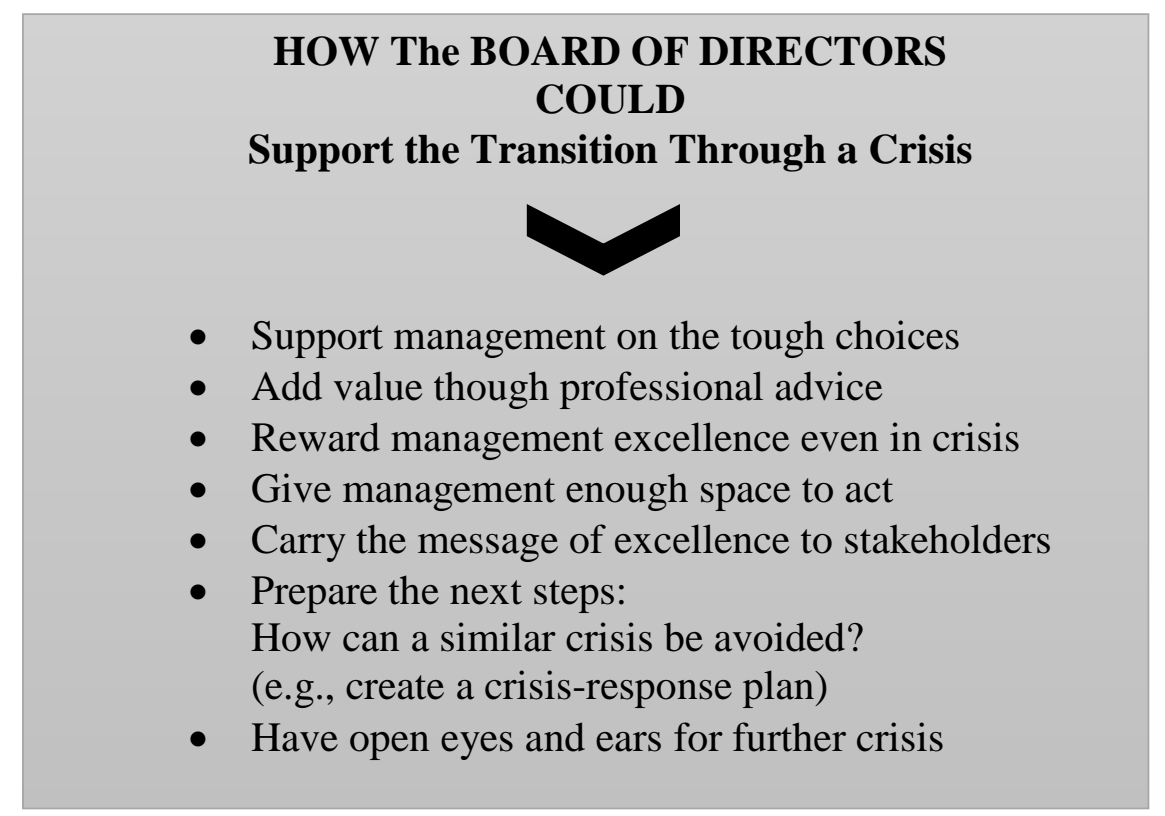

Figure 3. How the Board of Directors Could Support the Transition Through a Crisis

Source: author's own contribution 
How could the board prevent this?

On the regular agenda of the board there should be a significant focus and timeslot dedicated to analyzing the 'sensitive' or 'soft' factors. Ideally, an (independent) board member with coaching training or psychological studies/ experience would contribute a lot to overcoming this kind of barriers, which in our times are popping up more and more often.

As an intermediary conclusion to this chapter, we would offer a synthesis of the basic steps that a board could follow should any of the three factors described above happen and determine either an internal or an external crisis.

\section{POTENTIAL GUIDE TO DIMINISH THE PROBABILITY OF A CRISIS ARISING}

We need to be fair and admit that even in a company with a board that has overcome all of the above barriers and makes unbiased decisions, those decisions can turn out to be wrong in the end, since they are unavoidably still made under conditions of uncertainty.

Actions taken by competitors, the technological dynamics and changes in customer preferences can turn even the most-informed or the most neutral and least biased decision into a direction that is totally the opposite of what was initially intended.

For the long-term survival of a company it is vital that both the management team and the board of directors understand not to work under the assumption that everything will go according to plan. However basic the avoidance of such an assumption might look like, in real life human nature inclines towards a stability tendency, thus assuming that there will be no changes, no new developments by the competition and also no mistakes in implementing the plan agreed.

The board must design an organization that corrects mistakes and reacts to changes quickly.

This can only be accomplished if the board manages to create or support a culture of openness and transparency that is able to adjust rapidly.

Some specific actions that a board can take to minimize the impact of crises are listed below, emerged from own experience and from incipient discussions with the board members that will make the sample of a qualitative research for $\mathrm{PhD}$ degree.

While this little guide is obviously not complete, it is a starting point to approach the topic and it proves, once more, the utmost importance that the boards could have in preventing crises. While immersed in the day-to-day operations and targets and team \& financials management, the C-level executives might not always have the time - or the capacity - to have their antennae tunned to such signs. Instead, the board does have them. Or it should.

The potential guide that is the object of this article consists of five large sets of activities; each, in itself, could represent the subject of elaborated discussions, yet it is not the objective of this article to go into that much depth.

As such, our recommendation is that the boards focus on the following five sets of activities:

a) Look for early 'red' signs, that could indicate warning.

As stated above, most crises evolve over time, and board members have a special duty of keeping themselves informed and keeping their antennas open to receiving market trend signals.

Outsider board members could serve this role best, as they are not as deeply involved in business operations as insiders are, nor are the flooded with operational heavy load, and, as such, they can more easily see unusual patterns.

b) Use the market-available reports and order your customized financial and business-analysis reports.

The available tools could be early - respectively, historical signs - of a failure or of a coming crisis. These tools should definitely be analyzed and used in strategic decision-making: reports of external auditors, reports of internal auditors and compliance reports, reports on regulatory interventions and reports on industry trends. 
Needless to say that it is key that a company be able to take the necessary precautions so that to steer overcapacities as well as under-capacities.

c) Have two C-level executives in the board of directors.

Often, information reaching the board level is fragmented and lacks transparency.

It is thus highly useful that the boards are composed of one, ideally two C-level executives, especially in the cases of small companies acting in a very competitive field and, compulsory - as shown by reality -, in start-ups.

Until IPO, this structure is highly recommended, not only in emerging economies, but globally. At the startup level a small wrong decision (e.g. of which market to start first, of which customer to white-label) might be fatal for the entire business.

d) Always conduct robust risk evaluations.

Risk management in times when there is no apparent crisis is called 'sound risk management'(Konigsburg, 2019)

e) Build the company structure so that it is agile at any time.

Agility is not only the prerogative of small companies.

Agility is a mindset and a basic principle of creating a company structure that allows for fast and accurate information flow, for smooth and fast decision-making process (even when strategic topics, with big potential losses or big potential gains are in the game).

While agility is not the total opposite of 'control-freak-ness' that often is seen in family businesses or in companies that grew too much overnight, it is also not always similar to 'fast'.

An agile structure is one where the information flows smartly and constantly and where the business interests converge.

The board of directors can have a major contribution in making this happen, with guidance and vision.

\section{CONCLUSIONS}

A crisis is not a 'bad day in the office'. It can make or break organizations and careers. It will always require an executive-level response.

In a crisis, when the stakes are high and scrutiny is intense, the board has a unique role. Stepping in may be uncomfortable but stepping aside is not an option.

Good corporate governance structures and processes can help companies to be better prepared for crises.

It is the board's responsibility to supervise with precise regularity the implementation of all such processes and measures.

The conclusions converge towards the key role of corporate governance in preventing crises, or in making the company ready to confront them and emerge as healthy as possible from a severe crisis.

Common sense and common business life show that crises can happen despite good corporate governance structures.

Board members should ask rigorous questions and challenge any too-easy consensus, as a general rule. When too-easy consensus happens, it is either the outstanding internal communication between the stakeholders (please refer to the Figure 1 of this article), which is a rare situation, yet possible, or the root cause is the misinformation or lack of interest or attention from the board members.

Board directors should always have eyes-and-ears wide open and be on the lookout for early warning signs and utilize the available tools to analyze the well-being of the company. This way they could reduce the probability of a crisis hitting the company with full force.

Crisis management that the boards should always have on their (financial) radar starts long before a crisis hits. It should be an integral part of the wider organization's resilience measures and not simply something to deploy when all other options have failed. 
A simple guide to potential crisis prevention could look like this:

a) Look for early warning signs.

b) Use the market-available reports and order your customized financial and business-analysis reports.

c) Have two C-level executives in the board of directors.

d) Always conduct robust risk evaluations.

e) Build the company structure so that it is agile at any time.

The foreseen next steps in continuing the research on this topic, tackled shortly for the purpose of this article is a qualitative research with nominal members of the boards of acting companies in Romania, to validate the guide discussed above and also to add experience-driven insights to it.

\section{REFERENCES}

Boytsun, A., Deloof, M. \& Matthyssens, P. (2010). Social Norms, Social Cohesion, and Corporate Governance from: https://onlinelibrary.wiley.com/doi/abs/10.1111/j.1467-8683.2010.00829.x.-

Boytsun, A., Deloof, M. \& Matthyssens, P. (2010) Social Norms, Social Cohesion, and Corporate Governance Corporate Governance: An International Review, 19(1), 41-60

Corporate Governance during Crises. (n.d.). In onlinelibrary.wiley.com. Retrieved September 10, 2020, from https://onlinelibrary.wiley.com/doi/toc/10.1111/(ISSN)1467-8683.Crises-VI

Corporate Governance in Emerging Markets: Why It Matters to Investors - and What They Can Do About It (2020). Retrieved September 15, 2020 from: https://www.ifc.org/wps/wcm/connect/topics_ext_content/ifc_external_corporate_site/ifc+cg/re sources/private+sector+opinion/pso_22_melsa

Buzadzic, Z., M. (2018) Strengthening governance during crisis. Retrieved September 12, 2020 from: $\quad$ https://www.ifc.org/wps/wcm/connect/14e8598c-83ed-44fc-b0d4ed55641d0cf9/Strengthening_Governance_During_Crisis_Merima_Buzadzic.pdf?MOD=AJPE RES\&CVID=m6I1pG2.-

International Finance Corporation (n.d.), In International Finance Corporation. Retrieved September 9, 2020 from: https://www.ifc.org/wps/wcm/connect/Topics_Ext_Content /IFC_External_Corporate_Site/IFC+CG.

Klemash, S., Smith, J. \& Lee, J. (2018). The Board's Role in Confronting Crisis. Retrieved August 12, 2020 from: https://corpgov.law.harvard.edu/2018/10/07/the-boards-role-in-confrontingcrisis/.

Konigsburg, D. (2019). The board's role in crisis management. Retrieved July 30, 2020 from: https://www2.deloitte.com/content/dam/Deloitte/uk/Documents/risk/deloitte-uk-risk-global-onthe-boards-agenda-crisis-management.pdf.

McNulty, E., J. \& Marcus, L. (2019). What Boards Can Do to Prepare for Crises. Retrieved 2020 from: https://hbr.org/2019/06/what-boards-can-do-to-prepare-for-crises. Nu exista in text

Mishra, S. Institutional Shareholder Services (2019). Corporate Governance in Emerging Markets. Retrieved 2020 from: https://corpgov.law.harvard.edu/2019/02/24/corporate-governance-inemerging-markets-3/.

Riva, P., Danovi, A., Comoli, M. \& Garelli, A. (2017). Corporate Governance in Downturn Times: Detection and Alert - The New Italian Insolvency and Crisis Code. Retrieved 2020 from: https://www.intechopen.com/books/crisis-management-theory-and-practice/corporategovernance-in-downturn-times-detection-and-alert-the-new-italian-insolvency-and-crisis-cod.

Steger, U. \& Nedopil, C. (2015). The Incredible Adventures of Carla. Practical Guide for Nominee Directors Retrieved September 12, 2020 from: https://www.ifc.org/wps/wcm/connect/topics_ext_content/ifc_external_corporate_site/ ifc+cg/resources/guidelines_reviews+and+case+studies/the+incredible+adventures+of +carla++practical+guide+for+nominee_directors. 
Steger, U. \& Nedopil, C. (2010). Navigating Through Crises:A Handbook for Boards. Retrieved September 16, 2020 from: https://www.ifc.org/wps/wcm/connect/topics_ext_content/ ifc_external_corporate_site/ifc+cg/resources/guidelines_reviews+and+case+studies/navigating +through+crises+a+handbook+for+boards.

Sustainalytics (n.d.) Company ESG Risk Ratings. Retrieved September 9, 2020 from: https://www.sustainalytics.com/.

Tenev, S., Zhang, C. \& Brefort, L. (2002). Corporate governance and enterprise reform in china. building the institutions of modern markets. Retrieved September 2, 2020 from: https://books.google.ro/books?hl=en\&lr=\&id=PDs5Q8ZqVOMC\&oi=fnd\&pg=PR7\&dq=ifc+c orporate+governance\&ots=NMLwGVnkg8\&sig=E9txn4lyh1QorLUbC21KbQGXy7w\&redir_e $\mathrm{sc}=\mathrm{y} \# \mathrm{v}=$ onepage $\& \mathrm{q}=\mathrm{ifc} \% 20$ corporate\%20governance $\& \mathrm{f}=$ false.

Varfis, A. (2012). The Importance of Corporate Governance in Times of Crisis. Retrieved August 13, 2020 from: https://morrowsodali.com/news-events/articles/the-importance-of-corporategovernance-in-times-of-crisis.

Westlake, R. (2017). FOCUS Guidance for the Directors of Banks. Retrieved September $1^{\text {st }}, 2020$ from: http://westlakegovernance.com/wp-content/uploads/2017/02/GCGF___Guidance_for_ Directors_of_Banks_-_Focus_11_-_August_2013.pdf.

White, K. (2019). Ensuring good corporate governance in times of crisis. Retrieved September 12, 2020 from: https://www.national.ca/en/perspectives/detail/ensuring-good-corporategovernance-crisis/. 